\section{Submassive Pulmonary Embolus: Should Current Recommendations Be Revised?}

Received: March 21, 2016; Accepted: March 22, 2016; Published: March 31, 2016

\author{
Thommi G \\ Pulmonary Department, Creighton Medical \\ Center, Omaha, NE, USA
}

Corresponding author: Thommi G

\section{Editorial}

The incidence for pulmonary embolus $(P E)$ ranges from 400 to 600,000 patients per year in the US with a morality rate reaching up to $15 \%$ in the first three months. Patients with normal BP, 02 saturations and minimal SOB have a good prognosis and the current recommended therapy is adequate. Patients with massive PE with hypotension and severe hypoxia warrant thrombolytic therapy or catheter directed thrombolysis and / or embolectomy and fragmentation. Patients with submassive PE, however, do not necessarily need thrombolytic agents but current anticoagulant recommendations may not be adequate and sufficient to prevent chronic pulmonary HTN, associated morbidity and death secondary to persistent clot burden [1-4]. These patients have right ventricular strain diagnosed either with echocardiogram, EKG, high Troponin and high BNP. Authors have suggested treating these patients via catheter driven techniques with or without thrombolytic therapy $[5,6]$. Our patients with submassive PE who were clinically stable but with evidence of RV strain were treated with IV heparin therapy for 5 - 7 days then switched to Lovenox subcutaneously for 2 - 4 weeks keeping the antifactor $X a$ in the range $0.5 \mathrm{IU} / \mathrm{ml}$ to $1.2 \mathrm{IU} / \mathrm{ml}$. Oral anticoagulation was initiated if CT pulmonary angiogram (CTA) performed in approximately 2-4 weeks showed significant resolution of the embolus. However,
झ thommi9@gmail.com

Assistant Clinical Professor, Pulmonary Department, Creighton Medical Center, Omaha, NE, USA.

Tel: 4023900606

Citation: Thommi G. Submassive Pulmonary Embolus: Should Current Recommendations Be Revised? Insights Chest Dis. 2016, 1:2.

if CTA was denied and patients denied SOB, an echocardiogram was performed with a 6 min walk test to document resolution of RV strain, hypoxia and SOB before oral anticoagulants were prescribed. Patients were followed for several months and no recurrence of $P E$, associated morbidity or mortality was noted. We recommend further controlled studies to determine if prolonged therapy with lovenox is as effective as thrombolytic therapy or catheter techniques in preventing short and / or long term morbidity or mortality associated with submassive PE. 


\section{References}

1 Jaff MR, McMurtry MS, Archer SL, Cushman M, Goldenberg $N$, et al. (2011) Management of Massive and Submassive Pulmonary Embolism, Iliofemoral Deep Vein Thrombosis, and Chronic Thromboembolic Pulmonary Hypertension: A Scientific Statement From the American Heart Association. Circulation 123: 1788-1830.

2 Grifoni S, Olivotto I, Cecchini P, Pieralli F, Camaiti A, et al. (2000) Short-term clinical outcome of patients with acute pulmonary embolism, normal blood pressure, and echocardiographic right ventricular dysfunction. Circulation 101: 2817-2822.

3 Ramakrishnan N (2008) Thrombolysis is not warranted in submassive pulmonary embolism: a systematic review and meta-analysis. Critical Care and Resuscitation Journal 9: 357.
4 Worster A, Camala Smith, Shawna Silver, Michael DB (2007) Thrombolytic Therapy for Submassive Pulmonary Embolism? Annals of Emergency Medicine 50: 78.

5 Kucher N, Boekstegers P, Muller OJ, Kupatt C, BeyerWestendorf J, et al. (2014) Randomized, Controlled Trial of Ultrasound-Assisted Catheter-Directed Thrombolysis for Acute Intermediate-Risk Pulmonary Embolism. Circulation 129: 479-486.

6 Piazza G, Hohlfelder B, Jaff MR, Ouriel K, Engelhardt TC, et al. (2015) A prospective, Single-Arm, Multicenter Trial of Ultrasound-Facilitated, Catheter-Directed, Low-Dose Fibrinolysis for acute Massive and Submassive Pulmonary Embolism: The SEATTLE II Study. JACC 8: 1382-1392. 